\title{
LAS EMPRESAS MORALES DE JUAN DE BORJA INSTRUMENTO DE PEDAGOGÍA JESUÍTICA
}

\author{
JUAN DE BORJA'S EMPRESAS MORALES AS AN INSTRUMENT \\ OF JESUIT PEDAGOGY
}

Alejandro Martínez Sobrino, Cirilo García Román
Universidad del País Vasco / Euskal Herriko Unibertsitatea

\begin{abstract}
Juan de Borja (1533-1606), the son of Saint Francisco de Borja (1510-1572), who would later become the third Superior General of the Socity of Jesus, published a book of emblems with a pronounced moralistic content, with the title Empresas Morales (Prague, 1581), after a long and distinguished diplomatic career. It is a work that stands out, among other reasons, for the evidence that can be detected in it of the method of study implanted in the Ratio Studiorum by the Society. It was the system of study under which the author was educated. The purpose of our article is to show, through an analysis of the book's imprese, which at first glance exude a predominantly political nature, how the author imbricates and disseminates the precepts with which he was educated, by means of the combination of iconographical and textual elements.
\end{abstract}

KEYWORDS: Juan de Borja; Empresas Morales; Ratio Studiorum; Society of Jesus; Emblem; Impresa; Image; Text.

RESUMEN: Juan de Borja (1533-1606), hijo del que llegó a ser el tercer préposito general de la Compañía de Jesús, S. Francisco de Borja (1510-1572), publicó, tras una dilatada carrera diplomática, una obra de emblemas con fuerte contenido moral titulada Empresas Morales (Praga, 1581). Se trata de una obra que destaca, entre otras razones, por el poso que en ella se percibe del método de estudio implantado en la Ratio Studiorum por la Orden. Un sistema de estudio en el que fue educado su autor. El propósito de nuestra aportación es mostrar a través de sus empresas, que en principio exudan un carácter predominantemente político, cómo el autor imbrica y difunde, bajo la combinación de elementos iconográficos y textuales, preceptos con los que fue educado.

PALABRAS CLAVES: Juan de Borja; Empresas Morales; Ratio Studiorum; Compañía de Jesús; emblema; empresa; imagen; texto. 
Juan de Borja, autor de las Empresas Morales, nace el Bellpuig en 1533. Hijo de san Francisco de Borja, cuarto duque de Gandía y posteriormente tercer general de la Compañía de Jesús, recibe desde temprano una educación de clara orientación jesuítica. Primero, en el palacio ducal que la familia poseía en Gandía y que su padre había transformado en una casa de "recogida de religión" de la que se habían eliminado las «disciplinas y libros vanos», bajo la tutela de Francisco de Saboya, futuro jesuita (Ledda, 1970: 71); y después con su entrada a los 15 años en la recién creada Universidad de Gandía (1548), «origen y primera simiente [...], de todo un imperio educativo extendido por los jesuitas en todas las partes del mundo» (García Mahíques, 1998: 19).

Cuando en 1551, san Francisco de Borja renuncia al ducado y marcha a Roma con intención de entrevistarse con san Ignacio de Loyola, su hijo Juan viaja y permanece allí con él hasta su regreso, instante en el cual comienza una peregrinación como «mendigo por Christo y Predicador con palabra y ejemplo de su divina doctrina» por las tierras de Oñate (Nieremberg apud Ledda, 1970: 71). En ella también lo acompaña su hijo Juan, que posteriormente marchará a la Universidad Complutense a continuar sus estudios de Filosofía, lugar en el que no se desvinculará del todo de la formación jesuítica al permanecer junto al provincial de la Compañía de la Provincia Hispánica, el Padre Antonio Araoz (García Mahíques, 1998: 21). En 1552, Juan regresa a Gandía donde se casa con Lorenza de Oñaz y Loyola, nieta del hermano mayor de san Ignacio, y da comienzo a una larga vida de actividad pública en la que destacan sus embajadas en Lisboa de 1568 a 1575 y en Praga entre 1576 y 1581 . Periodo después del cual regresa a España, donde tras desempeñar algunos cargos más, muere en 1606 en el Monasterio de El Escorial. A partir de estos datos biográficos resulta muy difícil no concluir, por un lado, que, a pesar de que Juan de Borja no llegó nunca a formar parte de la Compañía de Jesús, las disposiciones e ideas que iban conformando la orden influirán con gran peso en el devenir de su vida y, por ende, en el desarrollo de su obra, y que, por otro, la influencia tanto de los preceptos ignacianos como, en especial, de los paternos es de hecho tal que sin tenerlos en cuenta resulta difícil la comprensión total de sus Empresas morales (García Mahíques, 1998: 18). Una ascendencia que no pasó desapercibida siquiera en su época, pues incluso así lo reconoce su sobrino en el prólogo a la segunda edición de las Empresas morales (Bruselas, 1680) donde afirma: "sacó sin duda los sólidos provechosos documentos que dexó a la posteridad en estas empresas» (apud Ledda, 1970: 72). ${ }^{1}$

Juan de Borja compuso las Empresas Morales a una edad avanzada y tras una dilatada carrera diplomática (García Mahíques, 1998: 36). No es hasta su estancia en Praga -entre 1576 y 1581 - en la corte del emperador Rodolfo II que dio forma a su obra, que será publicada por primera vez en $1581^{2}$ en la imprenta de Jorge Nigrin (García Mahíques: 1998, 30), y será la primera española sobre empresas, que, debido a la formación de su autor, se puede afirmar que de marcado carácter jesuítico. ${ }^{3}$ Así pues, no ha de sorprender el gran peso que tienen los preceptos de la Compañía, no sólo sobre la composición de las Empresas morales, sino también en el proyecto mismo del concepto que da título al trabajo. Una importancia que no se limita únicamente a la obra, pues al ser Juan de Borja el primer autor de empresas

1. Prólogo a Francisco de Borja, 1680, Empresas morales, Bruselas, fol. B.

2. Si bien las Empresas morales no se editan hasta 1581, es más que probable que la idea de su realización surgiera durante la estancia de Juan de Borja en Portugal, donde, como embajador, entabló unas fluidas relaciones con el pintor y dibujante Francisco de Holanda, García Mahíques, 1998: 37 y Ledda, 2015: 61.

3. Bien es cierto que en esta época ya estaban en proyecto obras emblemáticas dentro de la Compañía, por ejemplo, las Evangelicae historiae imagines (1593) y las Adnotationes et meditationes (1594) del Padre Nadal. No parece tener razón, por tanto, Dimler (1999: 21-22), cuando afirma que las del Padre Nadal son las primeras obras emblemáticas jesuitas. 
español y, por tanto, quien marque la pauta a seguir, sus rasgos principales acabarán por tintar de tal forma el género que se llega a hablar de Empresa Hispánica (Ledda, 1970: 68; García Mahíques, 1998: 33-34).

Juan de Borja, al igual que san Ignacio y san Francisco de Borja, estaba persuadido de que la retórica silenciosa del emblema persuadía con una eficacia mayor que el discurso más elocuente gracias al poder del sentido de la vista que no es sino el guía de los placeres más elevados del espíritu (Mathieu-Castellani, 1990: 6), por ello, distancia sus Empresas morales de la emblemática europea, en especial de la italiana, pues le retira sus rasgos lúdicos y le confiere, con la idea de convertirla en un instrumento didáctico, un peso moral, político y espiritual mayor (Ledda, 1970: 31; Ledda, 2015: 61-62; García Mahíques, 1998: 42). De este modo, el emblema pasa a ser un vehículo de transmisión de conceptos morales e ideológicos, como el propio Juan de Borja anuncia en la carta al lector (Borja-García Mahíques, 1998: 13): "de aprovechar en algo a los que las leyeren, por ser lo que se trata materia de buenas costumbres que es lo que tanto nos importa». ${ }^{4}$ Un rasgo que define la característica principal de la emblemática hispánica: la fijación en el alma de una enseñanza moral a través de la ejemplificación de un vicio que aparece recogido en una imagen (Ledda, 1970: 32).

Juan de Borja, para crear sus empresas, selecciona elementos de los dos modelos previos, la divisa y el emblema, y los combina en una nueva realidad, con lo que añade un tercer tipo de representación de una verdad intelectual a través de un símbolo sensible al que acompaña una leyenda que expresa su sentido. La fusión se produce tanto a nivel formal como de contenido. Así, mantiene del emblema que, del binomio formado por la imagen y el texto o cita, las palabras por sí solas posean un sentido pleno y acabado que se conjuga para la significación total con la imagen. Algo que no sucede en el caso de la divisa, en la que las palabras no se comprenden del todo si no es en colaboración con la figura. Además, confiere a sus empresas el valor universal propio del emblema, con lo que elimina un segundo rasgo de la divisa, el individualismo, pues la divisa es un símbolo circunscrito a un individuo o la expresión de algún rasgo que le concierne de forma particular. Esta nueva característica es exclusiva de su obra, ya que las empresas por lo general van dirigidas a un público concreto: religiosos, aristócratas, príncipes, caballeros... Con ello, Juan de Borja consigue configurar un híbrido entre la impresa, cuyo modelo sigue, y el sentido funcional del emblema (Ledda, 1970: 31; García Mahíques, 1998: 45).

Con todo, las señaladas constituyen las innovaciones más relevantes introducidas por Juan de Borja en la configuración del género, pero no son las únicas. Las cien empresas de la primera edición de sus Empresas morales (1581) proyectan enseñanzas bajo la forma prototípica del emblema, es decir, una fusión de pictura + mote + narratio, esto es, un grabado que recoge la idea a mostrar (la imagen), un lema que funciona de engarce nemotécnico (el mote) y una breve descripción (la narración), que en el emblema tradicional está constituido por un epigrama, normalmente en latín, pero que Juan de Borja, llevado por su didacticismo sustituye por una explicación en prosa en español en la que se exponen el contenido y el sentido de la imagen y en la que se dejan de lado las divagaciones eruditas y demás elementos del aparato filológico (García Mahíques, 1998: 45), pues, como él mismo señala en la carta al lector: "por no ser la autoridad ni la antigüedad de los auctores tanta que dexarlos de seguir importe mucho" (Borja-García Mahíques, 1998: 13). ${ }^{5}$ Aunque su falta

4. Objetivo que según Ledda (1970: 69), no logra: «Nonostante tali mutamenti e il dichiarato fine de aprovechar en algo a los que las leyeren, por ser lo que se trata materia de buenas costumbres que es lo que tanto nos importa, le imprese morali non potevano superare i confini di una ristretta cerchia d'élite».

5. Sigue el modelo establecido por el francés Pierre Cousteau en su le Pegme que también sustituye el epigrama 
de erudición sea únicamente aparente, como se verá más adelante, pues responde a «una escogida voluntad de autoconciencia creadora, de asunción de una responsabilidad total frente a la tarea emprendida", que no es otra si no la de engarzar su catálogo en el seno de una filosofía moral en la que se señalan los vicios y se ensalzan las virtudes ejemplarizantes (Cruz Suárez, 2015: 168).

Su empeño por ser didáctico impregna hasta tal punto su obra que determina incluso la disposición en página de los elementos, en especial la unión pictura-mote, consciente, al igual que los autores de cualquier género verbo-visual, de la función propositivo-conativa y del efecto percusivo del aparato visual que surgía gracias a que el primer impacto suscitado en el destinatario era visual (Ledda, 2015: 63). Así, la obra muestra en las páginas impares (el recto) el grabado, esto es, la pictura de la empresa dentro de una cartela junto al mote que se inserta en otra cartela menor encajada encima de la anterior, mientras que en las páginas pares (el verso) aparece la narración, de modo que el lector abriera el volumen por donde lo abriera, observaría en primer lugar la pictura. ${ }^{6}$ Gracias a esta distribución, las Empresas Morales se convierten en un práctico manual de enseñanza moral (García Mahíques, 1998: 48) en el cual la memorización de conceptos se produce a través de las idas y venidas desde el grabado a la prosa explicativa. Con este movimiento de vaivén, el lector recibe primeramente la impregnación visual de una imagen, que le transmite una verdad de orden teológico o moral, y posteriormente, una impregnación intelectual de su significado, de forma que en su mente se produce una unión indisociable de ambos, lo que el arte de la memoria denomina «lugar» (Chatelain, 1992: 333). Puesto que el signo-objeto, en la empresa «se dirige a la mirada del destinatario que, a través de un rápido proceso de previsiones y retroacciones, intenta reconstruir lo no formulado gráficamente y llegar a la satisfacción de haber acertado en la solución, pudiéndola confirmar en la declaración del autor, o paradójicamente, en caso de no haber acertado, sorprenderse y apreciar el significado no supuesto" (Ledda, 2015: 66-67).

Y es aquí donde entra en juego la idea que sobre la "composición de lugar» tiene san Ignacio de Loyola, para el que la compositio loci constituye el fundamento de lo que será una contemplación visual que engendra cierto tipo de prácticas. San Ignacio concibe la meditación a través de la percepción mental-sensorial -especialmente a través del sentido de la vista- de unas imágenes que, gracias a la observación de una serie de puntos, se configuran en una escena detallada y rigurosa del acontecimiento que se ha de contemplar (Campa, 1996: 46); puesto que la imagen representa un objeto del mundo real que significa al tiempo la idea y el concepto que simboliza (Mathieu-Castellani, 1990: 5). Y es esta composición de lugar que implantará en sus Ejercicios espirituales (1527) la que se encuentra en la base del emblema jesuita (Campa, 1996: 44), y la que se convertirá en un medio privilegiado de transmisión del discurso dogmático y normativo de la Iglesia (Chatelain, 1992: 324) al tiempo que un arma de combate efectiva frente a la herejía protestante (Campa, 1996: 44). Subyacía a este propósito el hecho de que con la Contrarreforma se produjo dentro del mundo católico el nacimiento de formas nuevas de leer que indisolublemente se unieron a los nuevos usos del libro y a las nuevas lecturas, grupo al que pertenece la emblemática religiosa jesuítica, pues fusiona en un solo cuerpo las estructuras técnicas de la meditación y las estructuras textuales del emblema (Chatelain, 1992: 349).

típico del emblema por una explicación en prosa que denomina narratio philosophica, cf. Chatelain (1992: 328 ). 6. Este modelo fue utilizado anteriormente en por Benito Arias Montano en la publicación de sus Humanae salutis monumenta, Amberes, Plantino, 1571 y reeditada en 1583, primer libro de emblemas católico, con el mismo objetivo (Chatelain, 1992: 330). 
Hasta el punto esta novedosa forma de meditación y lectura resultará exitosa que serán los jesuitas quienes se dediquen con mayor empeño y calidad a la publicación de libros de emblemas en términos globales (García Mahíques, 1998: 42). Y su éxito fue tan temprano que incluso san Francisco de Borja hizo suya esta idea de utilizar una imagen como apoyo a unos textos con una función retórico-mnemotécnica en los que se destaca la importancia que la memoria posee en los Ejercicios espirituales como la capacidad que mejor puede ayudar al cristiano en sus oraciones y meditación (Rodríguez de la Flor, 1978: 63). Aunque a diferencia de san Ignacio, san Francisco de Borja advirtió la conveniencia de objetivizar dicha compositio loci con el recurso a una imagen física (García Mahíques, 1998: 38-9), puesto que la imagen elimina la arbitrariedad del signo lingüístico y remite directamente al referente, con lo que la posibilidad de significar de los objetos representados en la imagen reduce el número de interpretaciones posibles (Mathieu-Castellani, 1990: 9). Razón por la cual san Francisco de Borja se propuso, basadas en los Evangelios, confeccionar y publicar acompañadas de grabados unas meditaciones que, por diferentes avatares, no vieron la luz hasta mucho más tarde (1675) y sin las ilustraciones (Campa, 1996: 45).

El elemento de la obra de Juan de Borja en que se aprecia en primer lugar la influencia jesuítica es en la selección de temas. La obra de por sí no muestra una ordenación de las empresas por materias y, en principio, no persigue con su disposición ofrecer unidad temática alguna. Con todo, se pueden encontrar algunos tópicos recurrentes -el menosprecio del mundo, el desengaño de las cosas del mundo, la virtud, la verdad, etc.- que ocupan su lugar en los Ejercicios Espirituales (Ledda, 1970: 73-77) y que no por casualidad se convertirán en tópicos del Barroco (Cruz Suárez, 2015: 168). Así, aunque no pueda defenderse que exista una unidad temática, sí que se pueden recomponer algunas ideas en secuencias, y reagruparse según motivos de intereses y de preocupaciones dominantes (Ledda, 1970: 70-71), por ejemplo, el retiro en uno mismo o el autoconocimiento que aparece en la empresa 97 («Nihil aliud superest») o en la 63 («Funiculi Vanitatum»). Unos conceptos sobre el auto-recogimiento y autoconocimiento que han sido recogidos de una forma u otra en los ejercicios y en los sermones jesuitas, y que, a pesar de tener un claro origen estoico, gracias al neoplatonismo ${ }^{7}$ se amoldan a la perfección al mensaje cristiano (Ledda, 1970: 73), ${ }^{8}$ hasta el punto de que fueron incluidos en los Ejercicios espirituales por san Ignacio (Rambla, 2008: 27) y aparecen también entre los preceptos impartidos por san Francisco de Borja:

[...] tanto más se aprovechará cuanto más se apartare de todos amigos y conocidos y de toda solicitud terrena; [...]. Del cual apartamiento se siguen tres provechos principales, entre otros muchos: el primero es que, en apartarse el hombre de muchos amigos y conocidos y, asimismo, de muchos negocios no bien ordenados, por servir y alabar a Dios nuestro Señor, no poco merece delante su divina majestad; [...], el tercero, cuanto más nuestra ánima se halla sola y apartada, se hace más apta para se acercar y llegar a su Criador y Señor; y cuanto más así se allega, más se dispone para recibir gracias y dones de la su divina y suma bondad.

Con todo, la influencia de las enseñanzas jesuitas no se limita a la utilización de los preceptos como temas de las empresas. Debido a la gran importancia que posee la imagen dentro de las concepciones formativas de la Compañía de Jesús, ${ }^{9}$ el elemento en que se aprecia

7. Rodríguez de la Flor (1978: 65): «[...], en la imagen de la memoria que la Compañía estimula para la formación de sus colegiales, hay restos perceptibles de formulaciones neoplatónicas expresadas en una predilección secular que los jesuitas han mantenido por la cultura de los símbolos».

8. No hay que olvidar que en este momento el mensaje estoico se estaba cristianizando (Bouzy, 2007: 128).

9. Rodríguez de la Flor, 201 1: 719: «La Compañía de Jesús, a la que, [...], podemos calificar como una auténtica 
con mayor prontitud y claridad la influencia de sus enseñanzas es en los grabados, como lo refleja además su disposición en página. ${ }^{10}$ Sin duda los jesuitas eran conscientes de que la imagen transmite, aunque de forma diferente, mayor conocimiento que las palabras, pues las representaciones simbólicas muestran el deseo humanista de hacer hablar al mundo mediante la figuración de lo inteligible en una forma circular: significado-representaciónsignificado (Mathieu-Castellani, 1990: 9).

Sin duda, la idea embrionaria de la obra y de cómo realizar los grabados que aparecen en ella está influenciada por el pintor y dibujante Francisco de Holanda, con quien Juan de Borja entabló una gran amistad durante su embajada en Lisboa, y quien también estaba influido por la espiritualidad de san Francisco de Borja, con quien compartía no sólo preocupaciones comunes en los campos de la emblemática y la iconografía bíblica, sino también un interés mayor por la oración mental que oral (García Mahíques, 1998: 37; Ledda, 2015: 61). Por ello, las ilustraciones de las empresas de Juan de Borja son severas, huyen del adorno excesivo y buscan un trazado concreto, nítido y fácil, en el que no se dibujan ni el paisaje ni el entorno situacional de los elementos. Por otra parte, recurren a la mitología y a la historia de forma muy limitada, razón por la cual su eficacia comunicativa se apoya en lo concreto al otorgar al significante el predominio de la pictura. Aunque esta austeridad de líneas compositivas de la imagen se base en razones "espirituales" y pertenezca en cierto modo a su último significado ascético-religioso (Ledda, 1970: 70), sin duda está en conexión con el espíritu de las sólidas y austeras enseñanzas paternas acerca de la parquedad en la vida terrena para provecho en la futura (Ledda, 1970: 77). A pesar de todo, debido a tal condensación, el mensaje en más de una ocasión se torna de difícil aprehensión, puesto que la imagen pierde su eficacia comunicativa y se torna obligatorio acudir al comentario (García Mahíques, 1998: 49-50).

A pesar de su simplicidad, las imágenes empleadas por Juan de Borja condesan de forma rica y variada ideas, consejos y disposiciones de los sermones de su padre o de los ejercicios de san Ignacio sin limitarse a la mera mención como tema del emblema y su reflejo en la pictura, pues, en ocasiones, fusiona más de uno o lo representa de una forma peculiar en la res picta [fig. 1]. Así en la empresa 39, donde nos habla de los peligros de la procrastinación (García Mahíques, 1998: 90) dibuja literalmente los últimos tres versos (64-67) de la sátira quinta de Persio: ${ }^{11}$

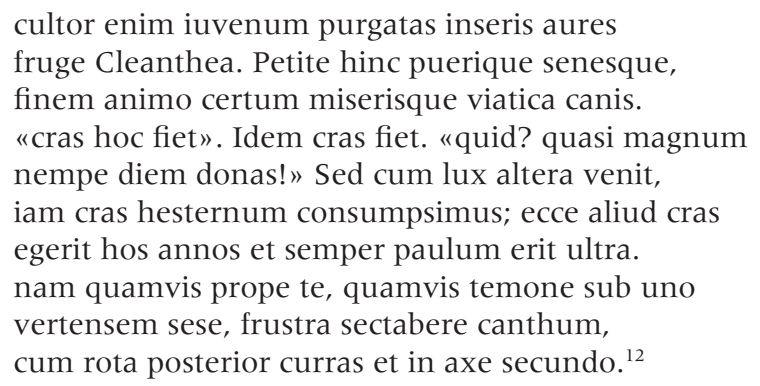

'internacional de la imagen', y que convirtió la pedagogía por imagines en una suerte de modo nostro o sistema propio de la Orden».

10. Para más información sobre los grabados, Lubomír (1992).

11. Para una explicación más extensa de cómo se llega a dicha conclusión, cf. García Román / Martínez Sobrino, 2007.

12. Per., 5, 64-72: «Pues, cultivador de los jóvenes, les siembras con la simiente de Cleantes las orejas bien purgadas. Venid a buscar aquí, jóvenes y viejos, una meta definida para el alma y un viático para las miserias de la vejez. 


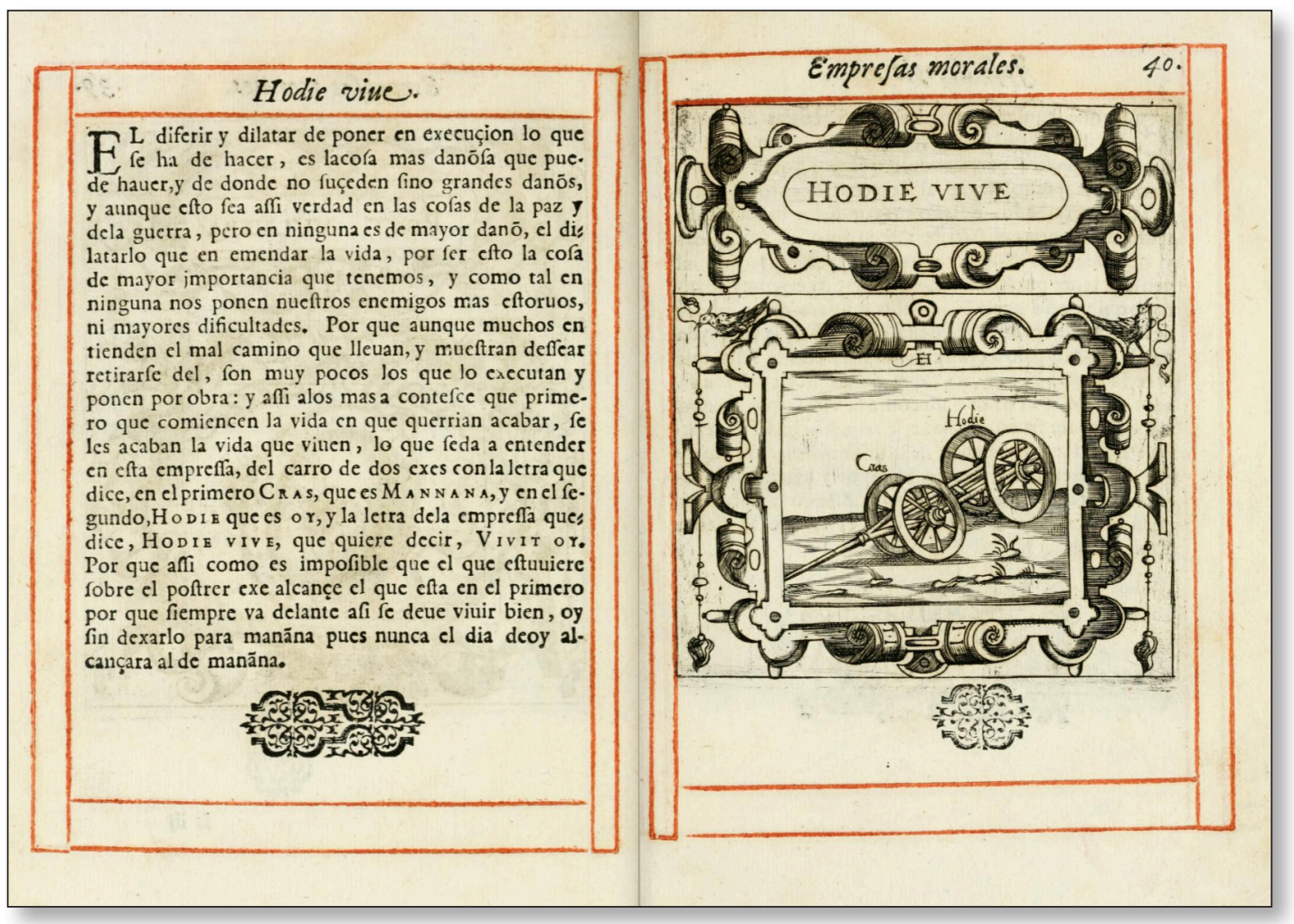

Fig. 1. Juan de Borja, Empresas morales. Empresa 39.

De esta forma tan gráfica Juan de Borja anuncia que al igual que en un carro de dos ejes es imposible que el trasero alcance jamás al anterior, si se procrastina el cambio de vida necesario, jamás se realizará, y así transmite el siguiente pasaje de los Ejercicios espirituales: «El diferir y dilatar de poner en ejecución lo que se ha de hacer es la cosa más dañosa que puede haber [...], pero de ninguna es de mayor daño el dilatarlo que en enmendar la vida [...]» (Rambla, 2008: 10), que es el motivo principal de la composición de los Ejercicios Espirituales: "Exercicios Espirituales para vencer a sí mismo y ordenar su vida, sin determinarse por afección alguna que desordenada sea» (Rambla, 2008: 27).

De modo que, aunque la imagen-foco sea fácilmente reconocible y reconocida [fig. 2], y pueda ser recolocada mentalmente en el contexto preciso, debido o a la alteración de uno de sus atributos, o a la asociación de objetos de varios campos, exige una re-lectura activa de los mitos y temas de las fuentes tradicionales que surge, como es el caso, del ingenio de un autor que absorbe de la cultura tradicional y contemporánea para rediseñarla (Ledda, 2015: 63-64). Aunque este no sea el modo único de realizarlo, pues, en la empresa 41, por ejemplo, Juan de Borja solapa varios significados para transformar en clave hermenéutica

-«Eso ya se hará mañana».

Y que mañana digas lo mismo ¿eh? - ¿Y qué? ¡Concedes un día como si fuera una gran cosa!, ¿no?»

Sí, pero cuando llega otro día ya tenemos gastado el "mañana» de ayer; y mira, otro "mañana» nos quitará los próximos años y siempre habrá otro un poco más allá. Pues, aunque la llanta gire justo a tu lado y bajo la misma lanza, en vano la perseguirás, porque eras la rueda trasera y corres en el segundo eje». 
con la que descubrir el concepto oculto la imagen (Dekoninck, 2007: 115), y otorgarle así diferentes niveles de lectura "que interpretar a la luz de otros parámetros» (García Mahíques, 1998: 123). En ella, bajo el lema Domus Optima aparece una tortuga que remite a la fábula de las bodas de Júpiter de Esopo. Unas nupcias a las que invitado el quelonio llega con gran retraso, e inquirido por el dios, responde con un «no hay mejor hogar que la casa propia». Parece que Juan de Borja está describiendo de este modo su propia situación como diplomático (García Mahíques, 1998: 94),13 al tiempo que de forma indirecta trata el tema de la soledad.

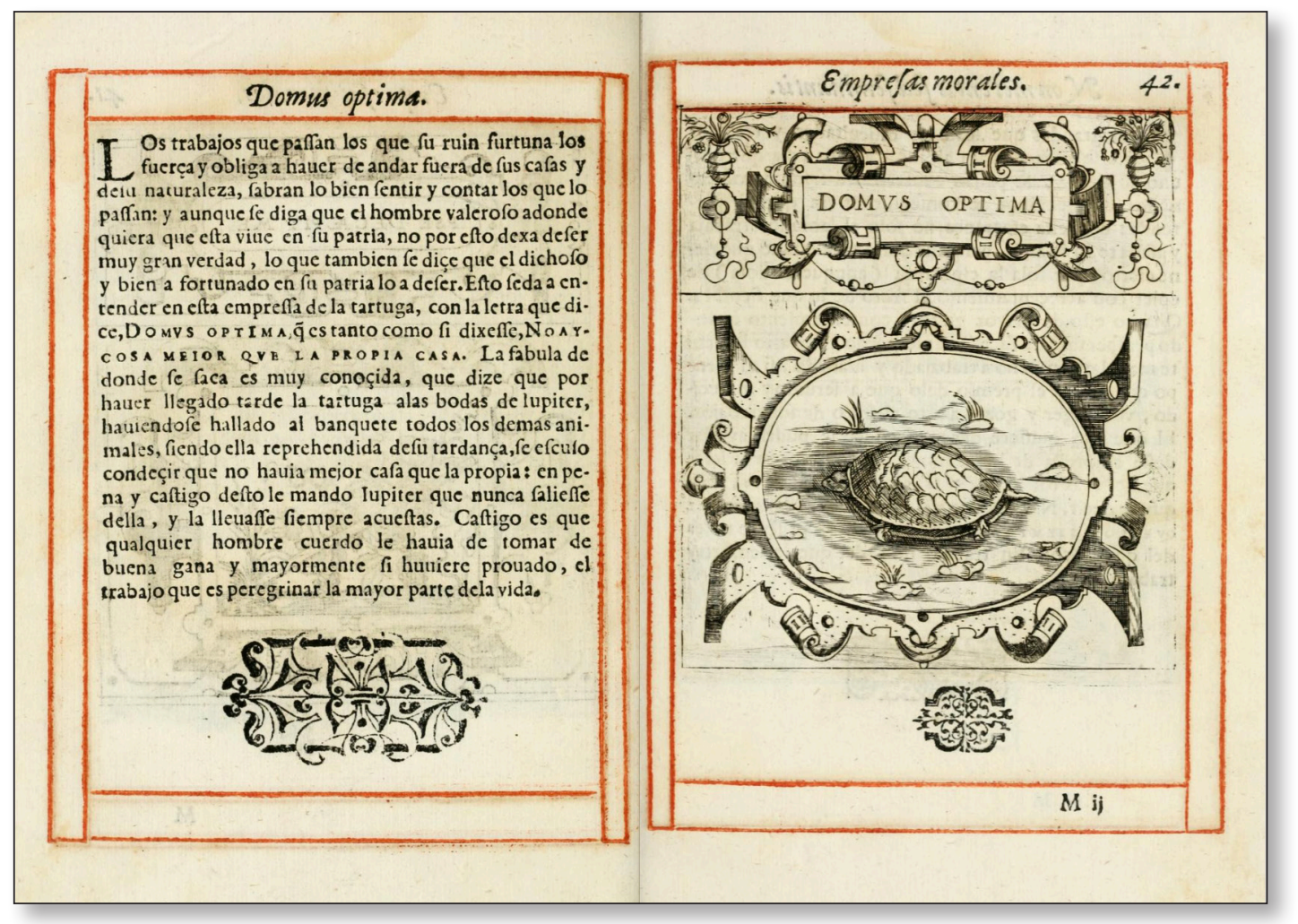

Fig. 2. Juan de Borja, Empresas morales. Empresa 41.

Una fusión conceptual de la soledad y recogimiento que aparece de nuevo en la empresa 60 [fig. 3] cuyo lema Nec te quaesiveris extra (Per., 1. 7) ${ }^{14}$ remite al aforismo griego "conócete

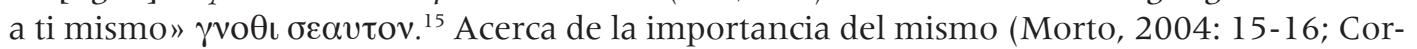
tés, 1988: 62), el propio Juan de Borja (García Mahíques, 1998: 132) decía:

13. Para una explicación más extensa cf. Martínez Sobrino (2013a).

14. Para un estudio más profundo de la influencia de Persio en Juan de Borja, cf. Martínez Sobrino (2007).

15. Es una imagen recibida durante su formación, como demuestra la siguiente cita tomada del comentario de Badio Ascensio a Persio (Martínez Sobrino, 2013b: 48): «non te quaesiveris extra quod alibi dicit tecum habita

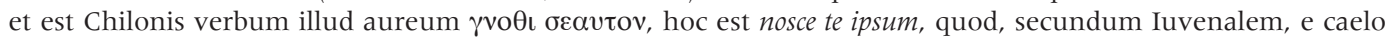
descendit et secundum Plinium oraculi meruit consortium». 


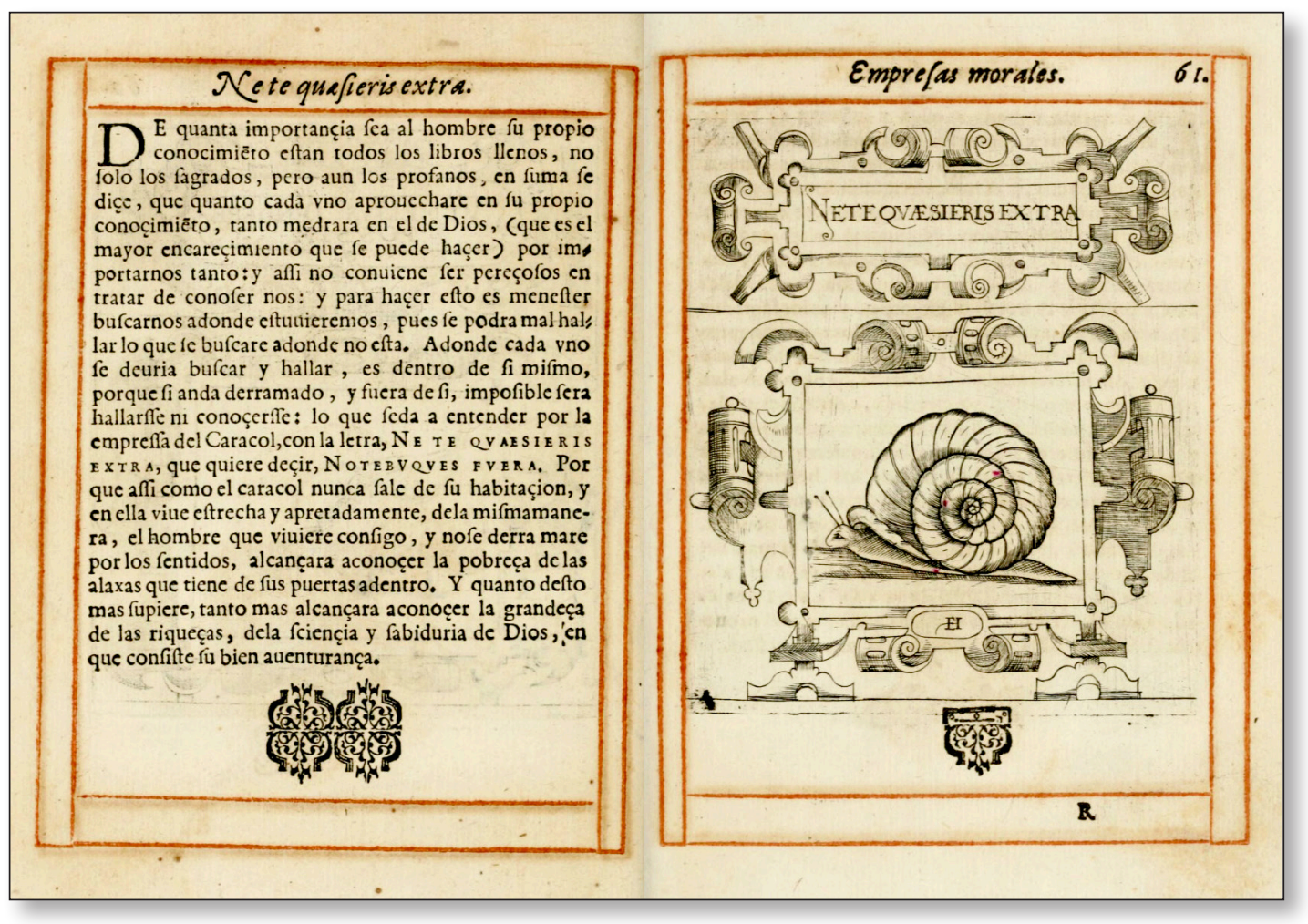

[fig. 3] Juan de Borja, Empresas morales. Empresa 60.

[...] de cuánta importancia sea al hombre su propio conocimiento, están todos los libros llenos, no sólo los sagrados, pero aún los profanos. [...] Porque así como el caracol nunca sale de su habitación, y en ella vive estrecha y apretadamente, de la misma manera el hombre que viviere consigo y no se derramare por los sentidos, alcanzará a conocer la pobreza de las alhajas que tiene de sus puertas adentro. Y cuando desto más supiere, tanto más alcanzará a conocer la grandeza de las riquezas de la sciencia y sabiduría de Dios, en que consiste su buenaventuranza.

De esta forma explicaba en la parte de la prosa descriptiva que la introspección era el significado perseguido con la del caracol en una atribución original a la imagen, (García Mahíques, 1998: 152).

Por otro lado, el limax o caracol, significado que en latín también se recoge bajo la forma choclea, simboliza la soledad ${ }^{16}$ y la idea del valor propio, pues según se creía con sus solos jugos, es decir a través de sus propios méritos, consigue alcanzar el grado supremo de dignidad. ${ }^{17}$ Objetivos ambos perseguidos con los Ejercicios Espirituales. De esta forma, aludía al siguiente principio de los Ejercicios Espirituales de la Compañía (Rambla, 2008: 23):

16. Picinelli (1979: 521): «Limax, tota hyeme intra concham suam delitescere solitus, a D. Josepho Pallavicino Abbate epigraphen recepit. DI ME STESSA MIS PASCO id est ME PASCOR AB IPSO. Ita homo, intra vitae solitariae angustias receptus, taciturnitate, ac corporis maceratione pascitur». Gómez Bravo y otros, 1999: 292: «El abad Giuseppe Pallavicino al caracol que suele encerrarse dentro de su concha durante todo el invierno le puso: DI ME STESSA MI PASCO, esto es, ME PASCOR AB IPSO (me alimento de mí mismo). Así el hombre retirado en la estrechez de la vida solitaria se alimenta del silencio y de la maceración."

17. Gómez Bravo y otros (1999: 290): «El señor doctor Giovanni Capponi a un caracol que se ha subido a un ele-

IMAGO, NÚM. 9, 2017, 73-86 
La primera anotación es que por este nombre, ejercicios espirituales, se entiende todo modo de examinar la conciencia, de meditar, de contemplar, de orar vocal y mental, y de otras espirituales operaciones, según adelante se dirá. [...] todo modo de preparar y disponer el ánima para quitar de sí todas las afecciones desordenadas y después de quitadas, para buscar y hallar la voluntad divina en la disposición de su vida para la salud del ánima, se llaman ejercicios espirituales.

Precepto que, por otra parte, había visto defender a su padre en sermones y oraciones, por ejemplo, en el tratado «Del propio conocimiento» (De Dalmases, 1964: 278-279):

El propio conocimiento ayuda mucho y es muy necesario al hombre, lo primero, para conocer a Dios, [...]. Lo segundo, para conocer las misericordias que conmigo ha usado y agradecerlas, porque misericordia es una virtud que remedia miserias; [...]. Lo tercero, para crecer en las virtudes, porque lo primero, ésta es la raíz de las virtudes y de aquí nace la humildad y el propio aborrecimiento y de ahí todas las virtudes; así como de no conocerse nace el tenerse en más de lo que es, y de ahí el amor propio, que es raíz de todos los vicios. Lo cuarto, para conservarse en la virtud, porque los que comúnmente caen es por la falta de su conocimiento, por cuyo defecto se levantan por lo que son.

Como se percibe en el pasaje, san Francisco de Borja concibe el autoconocimiento como un proceso en el que se avanza por distintos niveles hasta alcanzar la cima, es decir la visión divina. Idea que recoge asimismo en su «Sermón sobre S. Lucas, 19, 41-42» (De Dalmases, 1964: 62): "O, filii hominum usqueadeo gravi corde? Mira lo que eres, y desharás la rueda de tu vanidad. O si cognovisses et tu», expresión equivalente al nec quaesiveris extra de la empresa y que en el mismo sermón había utilizado poco antes (De Dalmases, 1964: 62):

Hallaremos, pues, por las palabras del tema que se llegó el Señor y vio la ciudad y lloró sobre ella y habló. Por estas cuatro cosas que hizo nuestro Redentor para nuestro conocimiento y para decirnos: si cognovisses et tu, podríamos hallar nuestro verdadero conocimiento, si bien le buscásemos. Y por esto, primero es menester ut appropinquet Christus, porque estando lejos de su gracia y de su lumbre, ni podemos conocernos ni conocerle.

Instrucción que aparece asimismo recogida en los Ejercicios Espirituales que han de recibirse de forma escalonada durante cuatro semanas (Rambla, 2008: 24). De este modo el caracol representaría en la empresa de Juan de Borja el proceso de ascensión interior en el que hay que proseguir de un modo lento y constante, y que quedaría recogido por la imagen del caracol bajo el término choclea que significa también escalera de caracol; pues (Rambla, 2008: 9): «[...] conviene que el ejercitante se abandone al lento proceso sin dejarse llevar por la prisa o la ansiedad de afrontar rápidamente dicho objeto de la elección». ${ }^{18}$

Pero la natural complejidad compositiva del emblema unida a la artificiosidad de la de Juan Borja hace que ésta no sea la única enseñanza transmitida por la imagen del caracol.

\footnotetext{
vado sitio de un muro le puso: SUCCO MEO (con mi jugo), para indicar al que con sus propios sudores, méritos y trabajos, y no con favores y ayudas ajenos, ha llegado a un alto cargo».

18. Concepto este último de la tardanza que también se ejemplifica mediante el caracol (Picinelli, 1972: 522): "Hinc desumpta Emblematis construendi occasione, cochleam depinxi, quae ad pyramidis verticem eluctata, epigraphen ferebat; AD CULMINA LENTE. Id quod non tantum in dignitatibus, aliisve negotiis, sed vel maxime etiam in scientiis assequendis contingere solet. S. P. Augustinus Noli festinare audire quod non capis, sed cresce ut capias"; o su traducción en Gómez Bravo y otros (1999): «Estos versos que dieron ocasión para formar una empresa con un caracol en la cima de una pirámide con el mote: AD CULMINA LENTE (hacia la cumbre lentamente), lo cual sucede no sólo en las dignidades y otros asuntos, sino también en el aprendizaje de las ciencias. San Agustín nos aconseja: ‘No te apresures en oír lo que no entiendes, sino que más bien crece para que entiendas'».
} 
Puesto que su habilidad como emblemista radica en su capacidad de velar los significados a expresar al tiempo que incita al lector en su búsqueda, debe pues desorientar e intrigar (Chatelain, 1992: 322). Lo que realiza aquí, pues la introspección es origen de otra virtud indispensable para el caballero de la Orden: la humildad. Cualidad requerida en los Ejercicios Espirituales ${ }^{19}$ por san Ignacio y por san Francisco de Borja en diferentes lugares, el sermón «del propio conocimiento» (De Dalmases, 1964: 279):

Lo tercero, para crecer en las virtudes, porque lo primero, ésta es la raíz de las virtudes y de aquí nace la humildad y el propio aborrecimiento y de ahí todas las virtudes; así como de no conocerse nace el tenerse en más de lo que es, y de ahí el amor propio, que es raíz de todos los vicios.

De nuevo, en el tratado decimoquinto titulado «otra consideración para lo mismo de nuestro propio conocimiento" (De Dalmases, 1964: 285):

El camino para la humildad y propio conocimiento es la humillación propia, la cual se ha de ejercitar en el comer, vestir, oficios, habla, asiento, etc. Ayudará para esto pensar quién es Dios y quién soy yo, y de aquí el humilde y que se reconoce, todo está colgado de Dios y no de sí.

O también una tercera vez en el «Sermón sobre Lucas 19, 41-42» (De Dalmases, 1964: 65-66):

Por cuanto los que verdaderamente se conocen, suelen estar llenos de gozo y alegría muy mayor de lo que estaría uno que se viese sacar de una cárcel muy oscurísima para ser monarca del mundo. Porque conociendo el hombre que por sus culpas merece estar debajo la tierra y se ve encima ¿no os parece que será alegre?

El caracol puede representar la humildad bajo la forma limax, -acis, ${ }^{20}$ que se encuentra etimológicamente ligada con limus, -i (lodo) según apunta Varrón en su De Lingua Latinae (7. 3. 64): limax ab limo, quod ibi vivit. De este modo, Juan de Borja relaciona este locus con la imagen de la humildad que ha transmitido por su padre en sus escritos (De Dalmases, 1964: 279):

Está el hombre como lo pinta David (Sal. 69.3), que dice, hablando de esta miseria: Infixus sum in limo profundo et non est substantia, veni in altitudinem maris et tempestas demersit me, esto es, Húndome en profundo cieno,I donde no puedo hacer pie; I me sumerjo en aguas profundas, I y me arrastra la corriente.

Por otra parte, al estar ligada etimológicamente la forma limax, -acis al lodo la imagen obtiene un grado mayor de rebajamiento. Lo que nos conduce a otro pensamiento querido a san Francisco de Borja (De Dalmases, 1964: 66):

[...] y la regla común para conocer si le tenemos o nos falta este conocimiento es mirar cómo nos aborrecemos; porque, si poco nos conocemos, poco nos aborrecemos; y si medianamente también nos conocemos, medianamente; y si mucho nos aborrecemos, es señal que mucho nos conocemos.

19. Rambla (2008: 10): «Parece, por lo demás, imprescindible, tanto por parte de la persona que los da como por parte de quien los hace, una actitud de profunda humildad y reconocimiento, tanto para evitar actitudes prometeicas de solapado orgullo o autosatisfacción como para no dejarse llevar por una pusilánime actitud que lleva a desconfiar del deseo de Dios de comunicarse a la persona humana».

20. Picinelo recoge también esta identificación (Picinelli, 1979: 520).

IMAGO, NÚM. 9, 2017, 73-86 
Lo que eventualmente redunda en una grandeza mayor y amplía las posibilidades de alcanzar la gracia divina (De Dalmases, 1964: 459):

y cuanto más humilde fuere, tanto será mayor el fruto que hará y tanto más agradará al Señor, que es el verdadero maestro de los predicadores humildes; el cual con el Padre y con el Espíritu Santo vive y reina eternamente.

Como se puede apreciar mediante los ejemplos vistos y, en especial con este último de la empresa 60, la artificiosa elaboración característica de Juan de Borja entreteje una compleja red de referencias que contempla diferentes niveles: en un primero, se resalta la importancia de la introspección en el plano religioso; en uno secundario, refleja la imagen del hombre pretendido por la Compañía de Jesús que sigue el modelo encarnado por su padre, que junto a san Ignacio conformó la Compañía de Jesús en los inciertos años de su nacimiento:21 humilde, pobre, casto y obediente. ${ }^{22}$ Modelo que representa asimismo el ideal de cortesano en la corte de Felipe II (García-Mahiques, 1998: 49).

Juan de Borja, por tanto, es un maestro en el aprovechamiento de los rasgos definitorios de la empresa, puesto que a través del obligatorio desciframiento gradual del mensaje que exige la res picta trasmite de forma metafórica tanto el proceso de formación ideal de los jóvenes como la culminación del mismo exigiendo del lector que busque en diferentes contextos -remotos y coetáneos- los elementos necesarios que le permitan desvelar una enseñanza o una realidad conocida (Ledda, 2015: 63 y 64), al aprovechar su autor la relativa oscuridad del emblema que permite sustituir con facilidad el horizonte de significación visto en un principio por el emblemista en uno nuevo que solapa y complementa el precedente (Chatelain, 1992: 324).

Así pues, la obra de Juan de Borja, a pesar de no ser propiamente una obra emblemática adscrita a la Compañía de Jesús, da muestras claras de la formación recibida por su autor, al tiempo que establece y fija los parámetros característicos tanto de la literatura emblemática española como de la emblemática propia de la Orden creada por san Ignacio: la transmisión de unos valores morales cristianos y católicos mediante el recurso a una combinación semánticamente pertinente surgida de la fusión de imagen, mote y texto.

21. Ryan (2008: 46): «Cuando Ignacio y sus más cercanos colaboradores escribieron las Constituciones de la Compañía de Jesús, Francisco de Borja garantizó la estabilidad interna en la entonces conflictiva Península Ibérica. Francisco de Borja salvaguardó la identidad ignaciana de la Compañía de Jesús, y su servicio al fundador fue fundamental para el éxito de la orden».

22. Ruiz Jurado (2012: 404): "Siguiendo paso a paso la vida del P. Borja en sus primeros años de sacerdote, desde su vuelta de Roma hasta su entrada en cargos de gobierno, hemos visto en él un sacerdocio extraordinariamente celoso, activo, fundado en una vida religiosa ejemplar, una consagración a Dios vivida cada día con ejemplar dedicación en pobreza, castidad y obediencia apostólicas, totalmente fiel a su superior el P. Ignacio, en su vida personal y en sus salidas apostólicas constantes.» 


\section{BIBLIOGRAFÍA}

Bouzy, C. [2007]. «El hombre sabio es un caracol: Una representación emblemática», en I. Arellano, M. Vitse (eds.), Modelos de vida en la España del Siglo de Oro. (Vol. II), El Sabio y el Santo, Madrid/Frankfurt, Universidad de Navarra/Iberoamericana Vervuet.

CAmpa, P. F. [1996]. "La génesis del libro de emblemas jesuita», en S. López PozA (ed.), Literatura emblemática hispánica. Actas del I Simposio Internacional (A Coruña, 1994), A Coruña, Universidade, 43-60.

Chatelain, J. M. [1992]. "Lire pour croire: mise en texte de l'embléme et art de méditer au VIIe siècle", Bibliothèque de l'école des chartes, tome 150, livraison 2, 321-351.

Cruz SuÁrez, J. C. [2015]. «Historieta arcana. Huellas del pensamiento barroco español en las Empresas morales de Juan de Borja", en J. M. Morales Folguera, R. Escalera Pérez, F. J. Talavera Esteso (eds.), Confluencia de la imagen y la palabra, Anejos de Imago 3, 167-176.

Dimler, S. J. [1999]. «Emblems», en J. B. Atteberry, J. Russell (eds.), Ratio Studiorum Jesuit Education, 1540-1773, Boston College, 20-24.

García Román, C., y Martínez Sobrino, A. [2007]. «Las fuentes Textuales de la pictura de la empresa 39 de las Empresas Morales de Juan de Borja», en J. Alonso Aldama, C. García Román, I. Mamolar SÁnchez (eds.), Stis ammoudies tou Omhrou. Homenaje a la Profesora Olga Omatos, Vitoria-Gasteiz, UPV/EHU (Anejos de Veleia), 267-277.

García Mahiques, R. [1998]. Empresas morales de Juan de Borja. Imagen y palabra para una iconología, Valencia, Ayuntamiento de Valencia.

- [2011]. "Imagen conceptual e imagen narrativa», en R. Zafra, J. J. Azanza (eds.), Emblemática transcendente, Pamplona, SEE/ Universidad de Navarra, 65-85.

Gómez Bravo, E., Lucas González, R., Skinfill Nogal, B. [1999]. Picinelli, F., El mundo simbólico. Serpientes y animales venenosos, Michoacán, Conacyt.

LEDDA, G. [1970]. Contributo allo studio della letteratura emblematica in Spagna (1549-1613), Cagliari, Università di Pisa.

- [2015]. «Celar, mostrar, desvelar...: estrategias de remodelización verbo-visual en la emblemática áurea», Janus 4, 58-85.

Martínez Sobrino, A. [2007]. "Pervivencia de la Antigüedad Clásica en la Emblemática hispánica. El caso de las Saturae de Persio en las Empresas Morales de Juan de Borja», en R. García Mahíques y V. Zuriaga Senent (eds.), Imagen y cultura. La interpretación de las imágenes como Historia cultura. Actas del VI Congreso Internacional de la Sociedad Española de Emblemática, celebrado entre el 16 y 19 de octubre de 2007 (2 Vol.), Valencia, Biblioteca Valenciana, Vol. II., 1063-1071.

- [2013a]. «La empresa 60 de las Empresas Morales de Juan de Borja. Posible origen textual de la imagen del caracol», Imago, 5, 91-99. <doi: 10.7203/imago.52607>.

- [2013b]. Estudio y edición crítica de los comentarios de Iodocus Badius Ascensius al poeta satírico Persio, Vitoria-Gasteiz, Anejos de Veleya, Series Minor 30.

Mathieu Castellani, G., [1990]. "Le retour de l'embleme», Littérature, 78, Anatomie de l'Emblème, 3-10.

Lubomír, K. [1992]. «La ilustración de las Empresas Morales de Juan de Borja: Erasmo Hornick", Ars longa, cuadernos de arte, 3, 9-12.

Persio [1988]. Sátiras, R. Cortes (trad.), Madrid, Cátedra. 
Picinelli, F. [1687]. Mundus Symbolicus in Emblematum Universitate Formatus, Explicatus et tam Sacris, quam profanis Erudiotinibus ac Sententis illustates, Coloniae Agrippinae, Hermanni Demen. [Ed. facsímille, "Emblematische Cabinet. Band VIII", Hildesheim-New York, Georg. Olms, 1979].

RAmbla, J. (ed.) [2008]. Los ejercicios espirituales de san Ignacio de Loyola. Una relectura del texto (i), Barcelona, Cristianisme i Justicia.

Rodríguez de la Flor, F. [1978]. "La compañía de Jesús: Imágenes y memoria», Hiperión, 3, 62-71.

- [2011]. «Pantalla total. La casa de ejercicios espirituales como locus del imaginario jesuítico», en R. Zafra, J. J. Azanza (eds.), Emblemática transcendente, Pamplona, SEE/ Universidad de Navarra, 719-729.

Ruiz Jurado, M. [2010]. "El sacerdocio jesuítico de s. Francisco de Borja (1551-1554)», en Francesc de Borja (1510-1572), home del Renaixement, sant del Barroc. Actes del Simposi Internacional, 391-404; y Revista Borja. Revista de L'institut internacional d'Estudis Borgians, 4, 2013. <http://www.raco.cat/index.php/RevistaBorja/issue/view/19707>.

Ryan, M. P. [2008]. El jesuita secreto: San Francisco de Borja, Valencia, Biblioteca Valenciana. 